\title{
Teaching Culture: Is It Possible to Avoid Pragmatic Failure?
}

\author{
Lucía Fernández Amaya \\ Pablo de Olavide University, Seville \\ lferama@upo.es
}

\begin{abstract}
The main purpose of learning a second language is communication. Nevertheless, many students are surprised when they realise that, in spite of having a perfect dominion of the L2 grammar rules, they have difficulties at interpersonal level when establishing a conversation with native speakers. Thus, pragmatics constitutes a fundamental element of language ability for L2 learners. However, L2 teachers often overlook pragmatics, due to the difficulty of its teaching, and instead focus on the grammatical aspects of language. The resulting lack of pragmatic competence on the part of L2 students can lead to pragmatic failure and, more importantly, to a complete communication breakdown. In this paper, several examples are used to illustrate how pragmatic failures affect the interpretation of messages and sometimes block communication completely, thus defeating the principal purpose of L2 acquisition. Finally, guidance is provided to encourage teachers to incorporate the necessary pragmatic and cultural aspects of L2 learning into their lessons in order to prevent students from making these types of mistakes.
\end{abstract}

\section{Introduction}

The main purpose of learning a second language is communication. Nevertheless, many students are surprised when they realize that, in spite of having a perfect dominion of 
the L2 grammar rules, they have difficulties at interpersonal level when establishing a conversation with native speakers.

This is due to the fact that even fairly advanced language learners often lack communicative competence (Hymes, 1964), that is to say, the necessary knowledge and experience to correctly use the sociocultural norms of the L2. Numerous comparative discourse studies (Blum-Kulka, 1982; Cohen and Olshtain, 1981; Gumperz and Tannen, 1979, among others) have shown that these norms vary from one culture to another. Therefore, a student requires more than just linguistic knowledge to communicate effectively in the L2 (Rose and Kasper, 2001; Jung, 2002, among others).

In order to progressively develop their communicative competence, students must be able to carry out some communicative tasks. These form a set of actions that have a concrete communicative purpose within a specific scope. For their accomplishment, different linguistic and discursive skills are used in context.

In this sense, Thomas (1983) sets out a two-part definition of linguistic competence, consisting of grammatical competence and pragmatic competence. The former refers to 'abstract' knowledge of phonology, syntax, semantics, intonation, etc.; the latter refers to the capacity to use a language effectively in order to fulfill a certain goal and to understand language in context. Therefore, the linguistic knowledge of a secondlanguage learner must be composed of both competences.

Thus, pragmatics constitutes a fundamental element of language ability for L2 learners. However, L2 teachers often overlook pragmatics, due to the difficulty of its teaching, and instead focus on the grammatical aspects of language. The resulting lack of pragmatic competence on the part of L2 students can lead to pragmatic failure and, more importantly, to a complete communication breakdown. As Blum-Kulka and Olhstain (1986: 169) point out “ ... pragmatic failure might carry serious social implications".

In this paper, several examples are used to illustrate how pragmatic failures affect the interpretation of messages and sometimes block communication completely, thus defeating the principal purpose of L2 acquisition. Finally, guidance is provided to encourage teachers to incorporate the necessary pragmatic and cultural aspects of L2 learning into their lessons in order to prevent students from making these types of mistakes.

\section{Pragmatic failure: theoretical considerations}

Thomas (1983: 91) defines pragmatic failure as "...the inability to understand 'what is meant by what is said"”. The author prefers the term 'pragmatic failure' to 'pragmatic error' because she thinks that a grammar error can be explained by means of prescriptive rules, while the nature of the pragmatic ambivalence is so, that we cannot say that the pragmatic force of a sentence is incorrect, but that has not been able to reach the speaker's communicative intention.

In the same way, Blum-Kulka y Olshtain (1986: 166) believe that pragmatic failure takes place “... whenever two speakers fail to understand each other’s intentions”. Thus, 
the listener can easily identify a grammar error, but we cannot say the same of pragmatic failure. If a non-native speaker is fluent, inappropriate speech may cause him or her to appear unintentionally rude, uncultured or awkward. For this reason, pragmatic failure is an important source of intercultural communication breakdown. Despite its significance, teachers and L2 text books writers have ignored pragmatic competence.

Thomas thinks that leaving pragmatics aside in L2 teaching is mainly due to two reasons:

a) pragmatic description has still not obtained the precision level of grammar, describing linguistic competence;

b) pragmatics - language in use - is a delicate area and it is not still very clear how it can be taught.

In spite of this, Thomas defends teaching pragmatics. She affirms that, although some grammars are beginning to make reference to pragmatics, the concept has not been clearly defined yet. Pragmatic failure is not noticed in the superficial structure of statements, but it becomes evident when analysing with the listener what force was $\mathrm{s} / \mathrm{he}$ trying to express. These are the type of discussions that should be carried out in L2 teaching, but to do that, Thomas considers that the students should be provided with the necessary tools first: teachers must develop a metapragmatic capacity in their students the capacity to analyse the language in a conscious way. For this, it is essential to make a distinction between two types of pragmatic failure: pragmalinguistic and sociopragmatic.

Pragmalinguistic failure takes place when the pragmatic force of a linguistic structure is different from that normally assigned to it by a native speaker. An important source of this type of error is pragmalinguistic transfer, where speech-act strategies are inappropriately transferred from L1 to L2. For example, using "Can you pass the salt?" in Russian to make a request, since this would be interpreted as a question to know if the listener has the physical ability to pass the salt.

Sociopragmatic failure, on the other hand, stems from the different intercultural perceptions of what constitutes appropriate linguistic behaviour. As Thomas states this type of pragmatic failure is more difficult to correct and overcome by the students since this involves making changes in their own beliefs and value system.

Some examples of sociopragmatic failure derive from:

a) The size of imposition: for example, what a person considers a free good (i.e. asking 'what time is it?') varies depending on the relations and the situation.

b) To make reference in the L2 to something taboo in that culture, although this topic can be openly discussed in the L1.

c) Power and social distance assessments that vary interculturally, for example, teachers in some cultures have more power over students than in others. 
I would like to show an example of sociopragmatic failure taken from my own personal experience. I was living in London with an Algerian who rented rooms and one of the other renters was Italian. One day, we were talking about mobile phones and the Italian man said that his had little coverage, swearing to describe this situation. The Algerian man's face suddenly changed and asked him to apologize to me. I very was surprised with what was happening, since I was used to listen to that type of expressions, and I had not paid attention to it. I said to the Algerian man that it was not necessary, which even made things worse: he explained that in his country nobody swears in front of a woman and those rules had to be followed in his house or we would have to leave. In spite of feeling completely ashamed, we stayed and that type of expressions were never used again when the house's owner was present. This man was a fanatic sexist to the eyes of the Italian, whereas I was able to understand what had happened without prejudging anybody, thanks to my pragmatic knowledge.

As can be seen, pragmatic failures not only affect language production but also understanding. A non-native speaker can interpret foreign language conversations following his or her own cultural norms, and will wrongly think that native speakers are being rude in situations where they are acting appropriately according to their linguistic community norms. The problem is knowing what kind of sociocultural norms are going to be followed in this type of interactions, in which people from different countries speak in English: I thought that the one of the language being spoken. But as can be seen by the example, although the Algerian man spoke in English, he evaluated the behaviour of the other interactants according to his own cultural and communicative norms.

The fact is that, just because we are speaking another language, we should not become a different person. As Pohl (2004: 6) claims "Striving for intercultural competence does not mean assimilation into the target culture". L2 students must be urged to observe and learn the cultural norms of the language that is being studied, but without changing their personalities. Nevertheless, we must let them know that this type of situations can happen. If they understand them, communication will not break.

Quite often, these errors have their origin in 'pragmatic transfer', which Kasper (1992: 207) defines in the following terms: “... pragmatic transfer in interlanguage pragmatics shall refer to the influence exerted by learners' pragmatic knowledge of languages and cultures other than L2 on their comprehension, production and learning of L2 pragmatic information”. In this sense, Ellis (1994) identifies several sociolinguistic factors that condition the occurrence of pragmatic transfer and indicates that students usually carry out speech acts, such as requests or apologies, in accordance with the sociolinguistic norms of their native language.

I will show now some examples of pragmatic failure, but in order to understand them correctly, I think it is necessary to introduce some concepts taken from Brown and Levinson's Politeness Theory 1978, 1987). This is structured towards the concept of face (taken from Goffman (1967)) defined as the public self-image that all competent adult members of a society want to claim for themselves. Brown and Levinson (1978, 1987) consider that this image, that is universal, can be negative (desire to have 
freedom to act and to be unimpeded in one's actions) or positive (desire of being appreciated and approved by others). According to the authors, during the interaction, the speaker tries to preserve his or her image and, at the same time, not to damage the other participant's. But this is not always possible, since there are certain speech acts that intrinsically threaten the public image (positive or negative) of the speaker or the listener: FTA (Face Threatening Acts). It is in these situations when the speakers, to try to avoid or, at least, to lessen the possible threat, have to put in practice the linguistic politeness strategies that Brown and Levinson (1987: 69) summarise in the following schema:

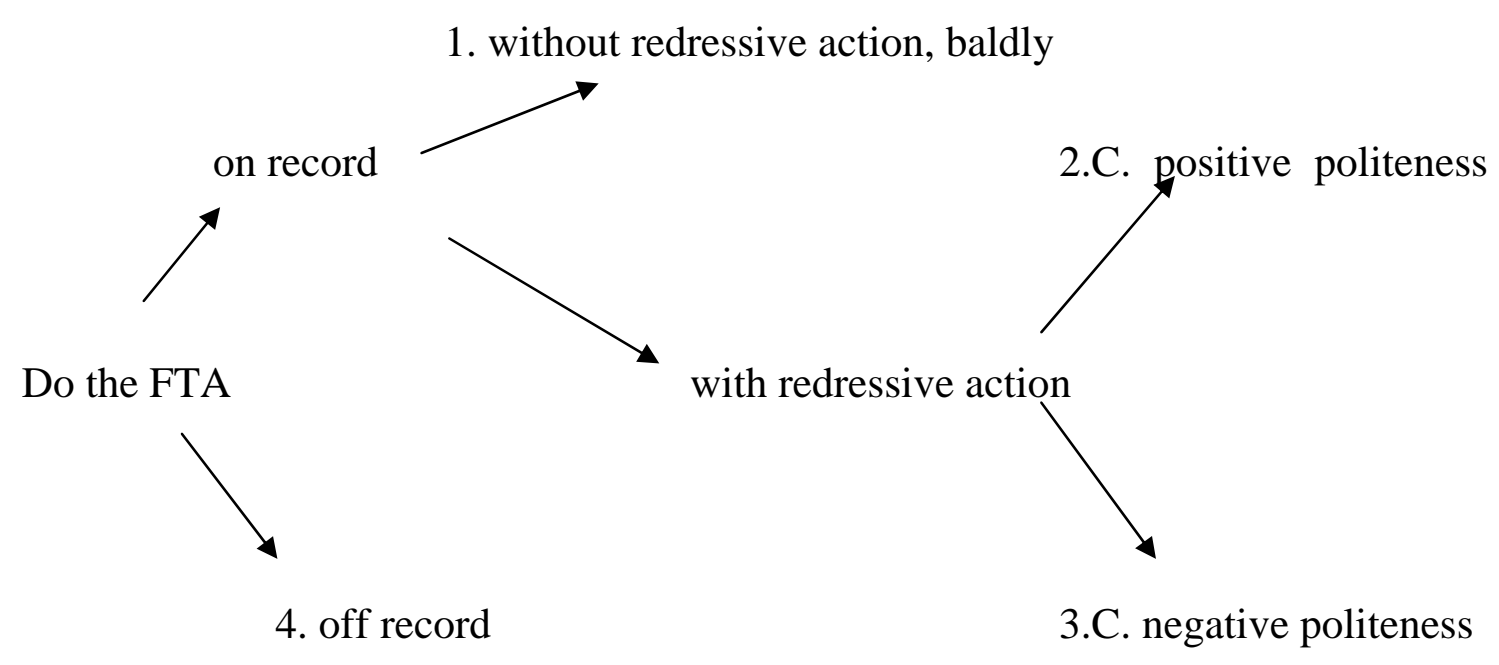

\section{Don't do the FTA}

The authors assure that, in similar circumstances, everybody will tend to use the same type of strategies. The more dangerous the potential threat of a FTA is, according to the speaker, the higher will be the number of the strategy chosen. Thus, the FTAs that suppose a minimum potential threat will have to be codified by means of the strategy number one (without redressive action, baldly) and the most dangerous ones will not be made.

According to Brown and Levinson (1978, 1987), the potential threat of a FTA depends on three factors: the relative power and the social distance between the speaker and the hearer and the absolute ranking of impositions of a FTA in a particular culture. This way, the weightiness of a FTA is calculated through the following formula: Wx = $\mathrm{D}(\mathrm{S}, \mathrm{H})+\mathrm{P}(\mathrm{H}, \mathrm{S})+\mathrm{Rx}$ where $\mathrm{Wx}$ is the numerical value that measures the weightiness of the FTA $x ; \mathrm{D}(\mathrm{S}, \mathrm{H})$ is the value that measures the social distance between the speaker and the hearer; $\mathrm{P}(\mathrm{H}, \mathrm{S})$ measures the power that the hearer has over the speaker; and $\mathrm{Rx}$ indicates the degree to which FTA $\mathrm{x}$ is considered an imposition in a certain culture. 


\section{Examples of pragmatic failure}

The three first examples are taken from the plays Look Back in Anger (LBA) and Time and the Conways (T\&C) written by J. Osborne and J. B. Priestley, respectively, and their corresponding translations into Spanish.

(1)

MRS C: Really, Madge, you are absurd. (T\&C, 56)

SRA. CONWAY: Realmente, Marta, eres absurda. (60)

In this example Mrs. Conway is criticizing her daughter Madge. This FTA threatens the daughter's positive image, since the speaker is indicating that she has not liked an act that the listener has carried out, putting into risk her desire to be appreciated and approved by others. In order to reduce this threat, the speaker uses a negative politeness strategy: the hedge 'really', which is maintained in the translation.

(2)

JIMMY: There's hardly a moment when I'm not - watching and wanting you. (LBA, 33)

JIMMY: No hay casi momento en que no me lo pase observándote, necesitándote. (39)

In this example, Jimmy is confessing his feelings to his wife and, in this way, he is threatening his own positive image: when revealing certain parts of his privacy to his wife, the speaker takes the risk that she does not keep due discretion. Thus, his confession could reach another person with whom Jimmy may not wish to share it and, as a consequence, this action can hurt his feelings. The speaker uses a negative politeness strategy to mitigate the threat that the FTA implies: the Quantity hedge 'hardly', with which Jimmy specifies that the information is not as precise as might be expected. In the translation, the same strategy is used.

(3)

JIMMY: ... For twelve months, I watched my father dying - when I was ten years old. He'd come back from the war in Spain, you see. (LBA, 57)

JIMMY: ... Durante doce meses, yo he visto morir a mi padre... cuando tenía sólo diez años. Él volvía de la guerra de España ¿entiende? (70)

In this example, Jimmy is again confessing intimate experiences to his listener, FTA that threatens his own positive image, as it was previously indicated. This threat is mitigated by means of a negative politeness strategy: the Manner hedge 'you see'. In the translation, negative politeness is also used: ¿entiende?

As can be seen in these examples, in English, several hedges are used to modify “... the degree of membership of a predicate or noun group in a set; it says of that membership that it is partial, or true in certain respects, or that it is more true and complete than perhaps might be expected”. (Brown and Levinson, 10987: 145) The 
translation into the Spanish is very literal and maintains the use of these expressions, which makes the speech not very natural. The explanation is that Spanish is a positive politeness language1 in which the general level of weightiness is low, that is to say, impositions are small, social distance is not an insuperable boundary to interaction, and relative power is not very great. Therefore such hedges are not necessary.

On the other hand, English is a negative politeness language in which all these values stay high and, therefore, the use of hedges is essential. The pragmatic meaning of linguistic expressions is conventionalised in different ways in different cultures. The three examples have been literally translated and, although propositional content equivalence has been pursued, illocutionary force equivalence has been left aside. The translator has not chosen pragmatic equivalents, which makes that all contextual effects are lost and pragmatic failures take place.

Examples 4, 5 and 6 are taken from Bou (1998), who quotes different authors.

(4)

This example of pragmalinguistic failure is taken from Richards y Sukwiwat (1983: 116), and makes reference to a situation in which a Japanese student has to express gratitude in English:

E: Look what I've got for you! (maybe a gift)

JE: Oh!, I'm sorry. (in Japanese, 'thank you' may not sound sincere enough)

E: Why sorry?

(5)

Garcés (1995) suggests that a Spanish student of English may say something similar to the following, when accepting an invitation to a party:

E: Will you be coming to my party on Saturday?

SE: Well

E: Well what?

(6)

- We must have lunch together some time.

- Let's do lunch.

- See you.

- Take care.

Wolfson (1981) indicates some non-native speakers of English have difficulties in correctly interpreting this type of routines, because they think that they are a real invitation to have lunch, in the case of the two first, for example. This makes them feel disappointed by the apparent lack of sincerity of their American friends, who, in fact, never invited them.

Something similar happens to some non-native speakers of Spanish, who draw the same conclusion from Spanish people who take leave saying Ya te llamaré, but they 
never phone. Pragmatic failure takes place because the listener is not assigning the right illocutionary force to this farewell formula.

(7)

Mrs. G: I’m sorry. (in Hebrew)

Mr. Y: Lady you could at least apologize.

This example, taken from Olshtain and Cohen (1989: 53), as the following one, represents a situation in which Mrs. G, native speaker of English living in Israel, is buying in a supermarket. When pushing her shopping trolley, she unintentionally bumps into an Israeli man. The woman tries to express an apology, but the linguistic codification chosen to carry out this speech act is not adequate, so that Mr. Y does not recognize it and pragmatic failure takes place.

(8)

A Hebrew speaker of English has forgotten a meeting with a friend and apologizes for this:

“I really very sorry. I just forgot. I fell asleep. Understand?” (Olhstain and Cohen, 1989: 64)

In this case, 'understand' is a direct translation from Hebrew, used by the speaker with question intonation looking for the listener's cooperation and creating a feeling of solidarity between both. Nevertheless, the effect in English is indeed the opposite, since this 'understand' sounds impertinent in this language. This is due to the fact that, whereas Hebrew is a language oriented towards positive politeness, English is oriented towards negative politeness, as we have already seen.

(9)

A (English) and B (Polish) have been travelling by train for a couple of hours. The conversation is decaying and A tries to liven it up:

A: I wonder how many trees there are in Poland.

[pause]

B: I cannot imagine who would want to know that.

In this example taken from Reynolds (1993: 1), B has not realized that A was engaging in phatic communion and has interpreted A's question literally without noticing it was something trivial.

This example taken from Blum-Kulka y Olshtain (1986: 168) takes place in Hebrew. A is a Norwegian teacher and B a Hebrew technician.

A: If it is not too much bother, could you please make a video cassette of this lesson.

B: When have I ever refused to prepare a cassette for you? I'm really surprised at you. 
In this case, the teacher's request is too elaborated and the technician interprets it as a complaint or criticism to his work.

\section{Teaching pragmatics}

Thomas (1983) points out that, making students understand the difference between pragmalinguistic and sociopragmatic failures, the teacher allows them to make pragmatic decisions to break the rules if they wish. Davies supports this idea when indicating: "Rather than being taught to be polite, learners should be given the possibility of choosing to be either polite or impolite". (Davies, 1986: 121)

In this way, for Thomas (1983) 'speaking English well' does not necessarily mean to follow the cultural rules. This author considers that the task of the teachers is to make sure that their students know what they are saying. In addition, the teacher has to take into account that pragmalinguistic failures can be corrected, while sociolinguistic failures are indicated and discussed, since these last ones show the learner's value systems and vision of the world.

These same conclusions can be applied to the examples previously commented. As we have seen, the pragmatic failures taking place in all the cases could have been avoided if the non-native speaker had had a metapragmatic capacity. Therefore, as Kasper \& Schmidt (1996: 160) say "pragmatic knowledge should be teachable”. There are numerous studies that prove this is so and instruction helps L2 learners in acquiring pragmatic competence (Billmyer, 1990; Kubota, 1995; Olshtain and Cohen, 1990; Wildener-Bassett, 1986; among others).

An example is the study carried out by Eslami-Rasekh et al. (2004) with 66 Iranian students of advanced English, focusing in three speech acts: request, apology and complaint. The students were divided in two groups: one control, receiving normal instruction (32 students) and another experimental to which, in addition to the normal classes, they received pragmatic instruction about 30 minutes of each 2 hour class period (34 students). Before the classes began, both groups were administered a questionnaire with 26 situations about the students' family, social and academic life. Each situation had four possible answers and only one was suitable from a sociopragmatic and pragmalinguistic point of view. Each correct answer was assigned two points. At the end of the course, the students were given another questionnaire, similar to the one made in the beginning.

The results were the following:

\begin{tabular}{|l|l|l|}
\hline \multicolumn{1}{|c|}{ GROUP } & Before classes & After classes \\
\hline EXPERIMENTAL & 30.00 & 46.00 \\
\hline CONTROL & 30.70 & 35.50 \\
\hline
\end{tabular}


Therefore, the results show that an explicit metapragmatic instruction facilitates the development of pragmatic abilities. But, what must the students learn to be competent from a pragmatic point of view? According to Jung (2002), the student must develop the following abilities:

1. Ability to carry out speech acts. It is necessary for the students not only to know how to choose the speech act needed in every situation, but also they should be able to choose the suitable linguistic codification to carry out this speech act. For example, in the Egyptian culture it is not appropriate to compliment pregnant women or children.

2. Ability to produce and interpret non-literal meanings.

3. Ability to use politeness strategies. As we have seen, these strategies may vary from one culture to another and it is necessary to recognize them

4. Ability to carry out discursive functions. For example, taking turns, pauses or silences, discourse markers, phatic utterances, etc ...

5. Ability to use cultural knowledge.

It is evident that these aspects of pragmatic competence overlap, that is to say, they do not operate independently.

\section{Concluding remarks}

It is my view that teachers should provide students with the necessary tools to make adequate pragmatic decisions in the L2. Students must learn that the codification of a certain message is subject to the conventions of use and these can vary from one linguistic community to another. For example, it would be important to make them see in which way the difference between cultures oriented towards positive politeness, like Spanish and those oriented towards negative politeness, like English, affects the production of messages.

Judd (1999) indicates that techniques for developing L2 pragmatic competence can be divided into three categories:

1. cognitive-awareness raising activities, such as presentation, discussion, and pragmatic-consciousness-raising techniques;

2. receptive-skills development by using teacher generated materials or natural data;

3. productive-skills teaching through role playing.

In my opinion, role playing is an excellent exercise in which students can carry out similar situations to daily communication. L2 learners must know that when a message takes place in a conversational interchange, this will be codified in a way or another depending on a series of contextual factors such as the participants, the place, the intention, the subject, etc. Therefore, a helpful exercise would be rehearsing the same 
role play several times but changing the elements of the communicative situation, so that students can understand how this affects the linguistic codification of the message.

An example of this type of exercise is the following, taken from Byon (2005: 1314):

\section{Situation [+P, -D]}

Informant A:

You are a freshman. You have an assignment due tomorrow and your computer won't start because of a virus. You have called several people but everyone is out, and the school computer room is packed with people already. You meet one of your close senior classmates down the hall, and you decide to ask him a favour.

Informant B:

You are a graduating senior. A freshman whom you know well asks you a favour. Assume that for personal reasons, you have to refuse any request from him/her.

\section{Situation [=P, -D]}

Informant A:

Because of a stomach flu, you were absent from last Friday's history class. So you decide to borrow notes from a friend to catch up. On the way to class, you run into him. What do you say?

Informant B:

You are a college student. While leaving class, you meet one of your close classmates, A. Assume that for personal reasons, you have to refuse any request from him.

\section{Situation [-P, -D]}

Informant A:

You are a faculty advisor for a student organization. You are in a meeting now with your students. You would like to take some notes, but you don't have a pen. One of your students whom you know very well is sitting next to you and might have an extra pen. What would you say to get this student to lend you a pen?

Informant B:

You are in a student organization meeting, taking notes. The professor, who is also the faculty advisor of the organization, happens to be sitting next to you. Assume that you have to refuse any request from the professor.

Another interesting exercise would be taking to class different L2 speech events and ask the students to record similar speech events in their L1, in order to make a contrastive analysis in which the possible similarities and differences can be discussed (BardoviHarlig 1992). The goal of this exercise is to raise students' pragmatic awareness by providing the students and teacher with realistic speech act information from their own environments. 
It goes without saying that we cannot explain our students all the possible changes taking place between L1 and L2, but we can sensitise them to expect cross-cultural differences and, this way, they will have more open minds. In this sense, Dash (2004:12) affirms: "Openness to different pragmatic interpretations consistent to sensitivities of various cultures and social groups would be something to keep in mind as well as an approach free of stereotypical judgments”.

\section{Notes}

1. Authors who consider Spanish as a positive politeness language and English as a negative politeness one are Walters (1979), Hickey (1991) Haverkate (1998), Portolés and Vázquez (2000) and Ardila (2004), among others.

\section{References}

Ardila, John (2004): “Transition Relevance and Overlapping in (Spanish-English) Conversational Etiquette”. The Modern Language Review 99 (3): 635-650.

Bardovi-Harlig, Kathleen (1992): "Pragmatics as Part of Teacher Education”. TESOL Journal,1(1), 28-32.

Billmyer, Kristine (1990): “'I Really Like your Lifestyle’: ESL Learners Learning How to Compliment”. Penn Working Papers in Educational Linguistics, 6 (2): 31-48.

Blum-Kulka, Shoshana (1982): "Learning to Say what you Mean in a Second Language: A Study of the Speech Act Performance of Learners of Hebrew as a Second Language”. Applied Linguistics 3 (1): 29-59.

Blum-Kulka, Shoshana and Elite Olshtain (1986): "Too Many Words: Length of Utterance and Pragmatic Failure”, SSLA 8: 165-180.

Bou Franch, Patricia. (1998): “On Pragmatic Transfer”. Studies in English Language and Linguistics 0: 5-20.

Brown, Penelope and Stephen Levinson (1987): Politeness: Some Universals in Language Use. Cambridge: Cambridge University Press.

Byon, Andrew S. (2005): “Teaching Refusals in Korean”. The Korean Language in America 10: $1-18$.

Cohen, Andrew D. and Elite Olshtain (1981): "Developing a Measure of Sociocultural Competence: The Case of Apology". Language Learning 31(1): 112-134.

Dash, Peter (2004): "Cross-Cultural Pragmatic Failure: A Definitional Analysis with Implications for Classroom Teaching”. Asian EFL Journal 6 (3): 1-17.

Davies, E. (1986): "Politeness and the Foreign Language Learner". Anglo-American Studies 6: 117-130.

Ellis, Rod (1994): The Study of Second Language Acquisition. Oxford: Oxford University Press.

Eslami-Rasekh, Zohreh. et al. (2004): "The Effect of Explicit Metapragmatic Instruction on the Speech Act Awareness of Advanced EFL Students”. TESL-EJ 8: (2): 1-11.

Garcés, Pilar (1993): "Revisión crítica de algunos de los postulados de la teoría de la cortesía lingüística propugnada por Brown y Levinson”. Quaderns de Filologia: Estudis Lingüístics I: 43-61. 
. (1995): “Discourse Markers”. Unpublished Paper.

Grice, H. Paul (1975): "Logic and Conversation". In P. Cole and J.L. Morgan, eds., Syntax and Semantics 3: Speech Acts. New York: Academic Press: 41-58.

Gumperz, John J. and Deborah Tannen. (1979): "Individual and Social Differences in Language Use”. In C.J. Fillmore, D. Kempler and W. S. Wang, eds., Individual Differences in Language Ability and Language Behaviour. New York: Academic Press, 305-325.

Haverkate, Hank (1988): "Politeness Strategies in Verbal Interaction: An Analysis of Directness and Indirectness in Speech Acts". Semiotica 71-1/2: 59-71.

Hickey, Leo (1991): “Comparatively Polite People in Spain and Britain”. ACIS 4 (2): 2-6.

Hymes, Dell (1964): "Directions in (ethno)linguistic theory”. American Anthropologist, 6 (3/2): 6-56.

Judd, Elliot L. (1999): "Some Issues in the Teaching of Pragmatic Competence". In E. Hinkel, ed., Culture in second language teaching and learning. Cambridge: Cambridge University Press, 152-166.

Jung, Ji-Young (2002): “Issues in Acquisitional Pragmatics". Working Papers in TESOL \& Applied Linguistics 2 (3): 1-13.

Kasper, Gabriele (1992): “Pragmatic Transfer”. Second Language Research 8 (3): 203-231.

Kasper, Gabriele and Richard Schmidt (1996): "Developmental Issues in Interlanguage Pragmatics”. In G. Kasper, ed., The Development of Pragmatic Competence. SSLA 18 (2): 149-170.

Kubota, M. (1995): “Teachability of Conversational Implicatures to Japanese EFL Learners”. IRLT Bulletin 9: 35-67.

Olshtain, Elite \& Andrew D. Cohen, (1989): "Speech Act Behavior across Languages". In H.W. Dechert and M. Raupach, eds., Transfer in Language Production. Norwood: Ablex Publishing Corporation, 53-67.

(1990): “The Learning of Complex Speech Act Behavior”. TESL Canada Journal 7: 45-65.

Osborne, John. (1957): Look Back in Anger. London: Faber and Faber. S.R.L.

(1960): Recordando con ira, trad. Victoria Campo. Buenos Aires: Editorial Sur,

Pohl, Gabriela (2004): “Cross-Cultural Pragmatic Failure and Implications for Language Teaching”. SLLT 4 1-10.

Portolés, José \& Ignacio Vázquez. (2000) "Mitigating or Compensatory Strategies in the Expression of Politeness in Spanish and English? 'Hombre'/'Mujer' as Politeness Discourse Markers Revisited”. In M. P. Navarro et al., eds., Transcultural Communication: Pragmalinguistic Aspects. Zaragoza: Librería General Sdad. Coop. Ltda.. de Artes Gráficas, 219-226.

Priestley, John. B. (1987): Time and the Conways and other Plays. Middle Esex: Penguin Harmonthsworth.

(1983): La herida del tiempo, trad. Luis Escobar. Madrid: Ediciones M.K.

Reynolds, Mike (1993): "Where the Trouble Lies: Cross-Cultural Pragmatics and Miscommunication". 27 $7^{\text {th }}$ International Conference on Cross-Language Studies and Contrastive Linguistics, 1-17.

Richards, Jack C. and Mayri Sukwiwat (1983): "Language Transfer and Conversational Competence". Applied Linguistics 4 (2): 113-125.

Rose, Kenneth R. and Gabriele Kasper (eds.) (2001): Pragmatics in Language Teaching. Cambridge: Cambridge University Press. 
Thomas, Jenny (1983): “Cross-Cultural Pragmatic Failure”. Applied Linguistics 4: 91-112.

Walters, Joel (1979): "The Perception of Politeness in English and Spanish". In C.A. Yorio et al., eds., TESOL '79: The Learner in focus. Washington, DC: TESOL, 288-296.

Wildner-Bassett, M. (1986): “Teaching and Learning 'Polite Noises': Improving Pragmatic Aspects of Advanced Learners' Interlanguage”. In G. Kasper, ed., Learning, Teaching and Communication in the Foreign Language Classroom. Aarhus: Aarhus University Press, 163-178.

Wolfson, Nessa (1981): "Invitations, Compliments and the Competence of the Native Speaker". International Journal of Psycholinguistics 8 (4): 7-22. 